\title{
Impacts of Different Sources of Biochar on Plant Growth Characteristics
}

\author{
Tazeen Fatima Khan, Mst Ummay Salma, Shahid Akhtar Hossain* \\ Department of Soil, Water and Environment, University of Dhaka, Dhaka, Bangladesh \\ Email: *sahossain@du.ac.bd
}

How to cite this paper: Khan, T.F., Salma, M.U. and Hossain, S.A. (2018) Impacts of Different Sources of Biochar on Plant Growth Characteristics. American Journal of Plant Sciences, 9, 1922-1934. https://doi.org/10.4236/ajps.2018.99139

Received: July 24, 2018

Accepted: August 20, 2018

Published: August 23, 2018

Copyright (๑) 2018 by authors and Scientific Research Publishing Inc. This work is licensed under the Creative Commons Attribution International License (CC BY 4.0).

http://creativecommons.org/licenses/by/4.0/ (c) (i) Open Access

\begin{abstract}
A net-house experiment was conducted to assess the impacts of different sources of biochar on growth and development of plant. Three different types of biomasses viz., cow dung, poultry manure and sewage sludge produced were used for the study. An upland leafy vegetable commonly known as kalmi (Ipomoea aquatica) was used for pot culture experiment. The biomass or biochar was applied to the soil at a rate of $5 \mathrm{t} / \mathrm{ha}$ and the pots were arranged following completely randomized design. A number of physical, chemical and physico-chemical properties of the soil, biochar, biomass and plant samples were analyzed in the laboratory. Biochar treated soils showed higher CEC than the corresponding biomass treated ones. Organic carbon in biochar treated soils was also higher. Total nitrogen contents of biomass treatments were higher than biochar treatments. Phosphorus, potassium and sulphur concentrations of the treated soils increased after harvesting. The paper discusses plant growth and agricultural crop production vis-à-vis biochar application, indicating that the materials might not exert similar positive effects as their biomass sources and thereby likely to jeopardize crop production and soil health.
\end{abstract}

\section{Keywords}

Net-House, Biochar, Biomass, Kalmi, Crop Production

\section{Introduction}

Soil is one of the basic resources and healthy soil is the foundation of the food system. Various approaches have been tested so far for maintaining quality of soil that ensures proper growth and development of plants as well as sustainable agricultural production. Fertile soils rich in organic matter are our best insurance against food insecurity and climate vulnerability [1]. Soil organic matter, 
the product of on-site biological decomposition, affects the chemical and physical properties of soil and its overall health. Its composition and breakdown affect soil structure and porosity, water infiltration rate, moisture holding capacity, diversity and biological activity of soil organisms and plant nutrient availability [2].

Recently, a charred material, biochar, came into the context of plant growth, soil quality and climate change mitigation. In recent years, a number of approaches have been made with biochar in this regard [3]. Although some of these approaches appeared promising but their field verification and carryover effects on plants remained to be further ascertained. The problems of the global environment, the recognition of the need to recycle natural resources and discovery of the high technology of agriculture have placed the biochar in the limelight. Biochar could be a good option as the high surface area and porosity are able to absorb and/or retain nutrients and water and also provide a habitat for beneficial microorganisms to flourish [3] [4]. Moreover, biochar takes the carbon captured by living plants and turns the biomass into solid form of char. Such processes appear to offer one of the most promising technologies for carbon capture, sequestration and combating global climate change. Being crucial in reducing waste, producing renewable energy, increasing plant yield, biochar has become the most important discovery in human history [4].

The use of biochar has, however, been argued to have some drawbacks, with some research reporting negative consequences on soil and crop production. Internationally, there is a large hue and cry whether biochar is equally good compared to that of its biomass [5]. Decreased growth and nutrient imbalances in plants were observed due to the application of freshly prepared biochar into the soil [6]. Thus, the effects of biochar on growth of plants need to be assessed. The present study was undertaken to study the impacts of different sources of biochar on the growth of kalmi (Ipomoea aquatica) plant.

\section{Materials and Methods}

\subsection{Sampling Site}

The soil sample was collected from a local vegetable field located in Jagir Dighulia village in Atigram union in Manikganj district with geo-location of $23^{\circ} 51.884$ $\mathrm{N}$ and $90^{\circ} 06.219 \mathrm{E}$. The soil was a non-calcareous grey floodplain belonging to the Melandaha series. The USDA family code of the soil is loamy, mixed, nonacid, hyperthermic; taxonomy code is Typic Endoaquents and the FAO-UNESCO legend is Gleysols (Eutric Gleysols).

\subsection{Collection, Preparation and Processing of Soil Sample}

The bulk soil sample representing $0-15 \mathrm{~cm}$ depth from surface was collected by the composite sampling method as suggested by the United States Department of Agriculture [7]. The soil sample was processed following the standard procedures [8]. The collected soil samples were dried in air (at $\sim 40^{\circ} \mathrm{C}$ ) after being 
transported to the laboratory. After air-drying, a portion of the sample containing the larger and massive aggregates was ground by gently crushing with a wooden hammer. Ground samples were passed through a $2 \mathrm{~mm}$ stainless steel sieve. The sieved samples were then mixed thoroughly and stored in labeled plastic containers until required for various physical analyses. Likewise, another portion of the soil sample was further ground, passed through a $0.5 \mathrm{~mm}$ sieve, then mixed thoroughly and finally stored for various chemical and physico-chemical analyses.

\subsection{Collection and Processing of Biomass Samples}

Cow dung and poultry manure were collected from a dairy and a poultry farm in Gazipur district. Sewage sludge was collected from Pagla Sewage Treatment Plant located in Narayanganj, Dhaka. Cow dung, poultry manure and sewage sludge was dried in air for several days. After that, they were grounded with wooden hammer and screened through a $0.25 \mathrm{~mm}$ stainless steel sieve. The sieved samples were then mixed thoroughly for making composite sample and were preserved in plastic containers.

\subsection{Production and Processing of Biochar}

A big earthen pot was taken and metal wires were arranged in a criss-cross arrangement over the pot so that it can support the small pots. Individual biomass was placed layer by layer in small earthen pots. These pots were covered with earthen lids. 4 - 5 pots were placed on the wire arrangement in such a way that pots were uniformly heated from all sides. The temperature was maintained at about $100^{\circ} \mathrm{C}$. Finally, fire was lighted and accelerated time to time by adding wood chips and kerosene oil. After about an hour, when the biomass was turned to biochar, fire was stopped. These biochar looked like powdery ash and was black in color with large surface area. The lid of the pot was not opened until it cooled down completely. After cooling of the biochar, lids of the pots were opened, screened through $0.25 \mathrm{~mm}$ sieve.

\subsection{Pot Culture Experiment}

An upland leafy vegetable commonly known as kalmi (Ipomoea aquatica) was used for pot culture experiment. A total of 21 pots were arranged in the net house following completely randomized design (Table 1). Among them nine pots were supplied with different types of biomass and other nine pots with biochar. The pots were washed properly with water and dried in sunlight. There was no hole at the bottom of the pot. Air dried $5 \mathrm{~mm}$ sieved $2 \mathrm{~kg}$ soil samples were put in $3 \mathrm{~kg}$ sized pots and was kept in the sunlight for 15 days. Biochar and biomass were applied a rate of $5 \mathrm{t} / \mathrm{ha}$ i.e. each pot received $5 \mathrm{gm}$ of biochar or biomass. Nitrogen, phosphorus, potassium and sulphur were supplied from urea, TSP (Triple Super Phosphate), MP (Murate of Potash) and Gypsum fertilizers respectively according to the recommended dose of fertilizers. Certified, 
Table 1. The design of pot arrangements and treatment symbols.

\begin{tabular}{cccc}
\hline Sample name & Treatment & Rate of application & Designation \\
\hline \multirow{3}{*}{ Biomass } & Cowdung biomass & $5 \mathrm{t} / \mathrm{ha}$ & $\mathrm{CM}$ \\
& Poultry manure biomass & $5 \mathrm{t} / \mathrm{ha}$ & $\mathrm{PM}$ \\
& Sewage sludge biomass & $5 \mathrm{t} / \mathrm{ha}$ & $\mathrm{SM}$ \\
\multirow{3}{*}{ Biochar } & Cow dung biochar & $5 \mathrm{t} / \mathrm{ha}$ & $\mathrm{CC}$ \\
& Poultry manure biochar & $5 \mathrm{t} / \mathrm{ha}$ & PC \\
Control & Sludge biochar & $5 \mathrm{t} / \mathrm{ha}$ & $\mathrm{SC}$ \\
\hline
\end{tabular}

registered seeds of kalmi were procured from local market and 9 - 10 seeds were sown in each pot. The plants were irrigated with water in frequent intervals. Weeds were removed manually. Adequate plant protection measures were taken during the growing period. Visual observation viz., height, growth, leaf structure, leaf color, deficiency or toxicity symptoms, pest or insect infestations etc. were noted during the growing period of plants.

\subsection{Collection and Preparation of Plant Samples}

The kalmi plants were allowed to grow for 45 days. Sampling of plants was done by uprooting them carefully from the pots. The roots were first washed by tap water and then by deionized distilled water. The plant samples were separated into two parts: roots and shoots. Length of the collected shoots samples were noted down. The fresh weights were taken. The samples were first air dried and then oven dried at $70^{\circ} \mathrm{C} \pm 5^{\circ} \mathrm{C}$ for 48 hours and the dry weight of the plant samples was measured. The dried samples were then ground with mortar and pestle. The ground samples were mixed thoroughly and passed through a 0.25 $\mathrm{mm}$ sieve and kept in plastic containers for further chemical analyses.

\subsection{Laboratory Analysis of Soil, Biomass, Biochar and Plant Samples}

Various physical, chemical and physico-chemical properties of the soil as well as the biochar, biomass and plant samples were analyzed in the laboratory. The particle size analysis of the soil was carried out by hydrometer method [9]. The textural classes were determined by Marshall's triangular co-ordinates. $\mathrm{pH}$ of the samples were measured electrochemically by using a glass electrode $\mathrm{pH}$ meter at a ratio of 1:2.5 for soil and 1:15 for biochar and biomass. The CEC of soil, biomass and biochar samples were determined by $1 \mathrm{M}$ ammonium acetate extraction method [10]. Total organic carbon was determined by wet oxidation method of Walkley and Black [11]. Total nitrogen was determined by Kjeldahl's digestion method with concentrated sulfuric acid $\left(\mathrm{H}_{2} \mathrm{SO}_{4}\right)$ [12]. Available phosphorus was determined by extracting the samples using Bray and Kurtz method $(\mathrm{pH}<6.0)$ and Olsen method $(\mathrm{pH}>6.0)$ then the extracts were used to estimate 
P colorimetrically by following the blue color method using ascorbic acid by spectrophotometer at $880 \mathrm{~nm}$. Available $\mathrm{S}$ was determined by extracting the samples with calcium dihydrogen phosphate monohydrate $\left[\mathrm{Ca}\left(\mathrm{H}_{2} \mathrm{PO}_{4}\right)\right.$ and then the extracts were analyzed with a spectrophotometer at $420 \mathrm{~nm}$. Available $\mathrm{K}$ was determined by a flame analyzer after extracting the samples with $1 \mathrm{M}$ ammonium acetate at $\mathrm{pH}$ 7.0. Total $\mathrm{P}$ content of the samples were determined colorimetrically using a spectrophotometer at $490 \mathrm{~nm}$ by developing yellow color with vanadomolybdate after digesting the biomass with ternary acid mixture. Total sulphur content of the samples were determined turbiditimetrically by a spectrophotometer at $420 \mathrm{~nm}$ after digesting with concentrated nitric and perchloric acid.

\subsection{Data Analysis}

All data were statistically analyzed by using Microsoft Excel (version 2013) and SPSS (version 24) software.

\section{Results}

\subsection{Effects on Overall Growth of Plants}

It was found that due to the conversion of biomass to biochar, most of the parameters of biochar differed significantly from its source of biomass. Among these treatments kalmi growth was best under cow dung biomass (CM) treatment while it was worst under cow dung biochar (CC) treatment. Under other treatments growth was average in general though growth was better in control. Height of the plant was better grown on poultry manure biomass treated soils compared to that of biochar treated ones. However, the result was opposite in case of sludge. Number of leaves was almost same as control in sludge biochar than sludge biomass (SM). For poultry manure, number of leaves was almost same in both biomass (PM) and biochar (PC) but lower than control.

\subsection{Fresh and Dry Matter Production}

It was found that shoot length of kalmi differed significantly at $0.1 \%$ level due to the effects of all treatments. The fresh and dry matter productions of kalmi as affected by various biomass and biochar treatments were measured. It was observed that the weight of fresh and dry matter of kalmi was highest in cow dung biomass treated soils while the lowest in cow dung biochar treated ones and for other treatments dry matter production was lower than control (Figure 1 and Figure 2).

\subsection{Effects on CEC}

It was observed that CEC of biochar treated soils (CC, PC and SC) was greater or same compared to their respective sources of biomass (CM, PM, SM) treated soils (Figure 3). The highest CEC was found in cow dung biochar (CC) treated soils which was also greater than control. 


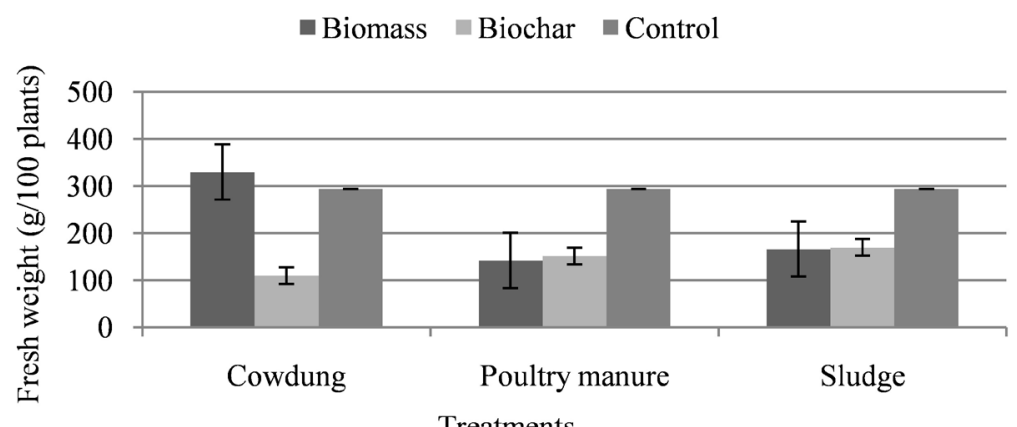

Figure 1. Comparison of fresh weight between different treatments.

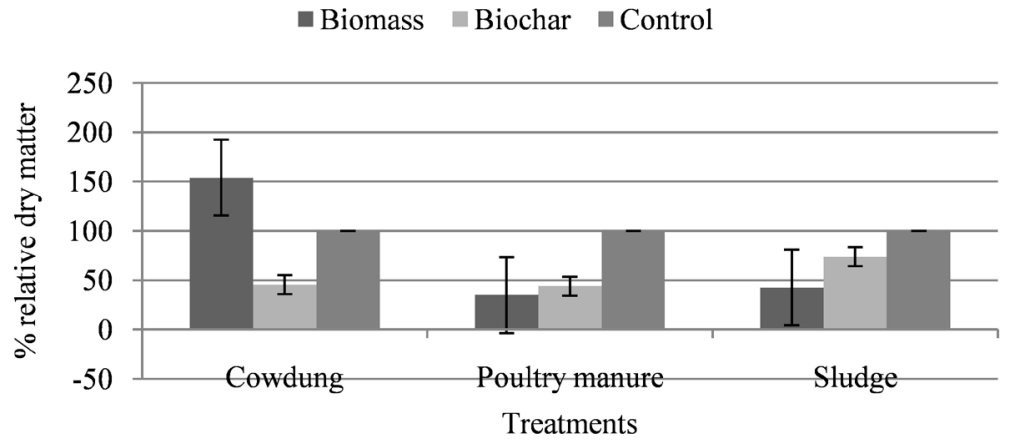

Figure 2. Comparison of $\%$ relative dry matter between treatments.

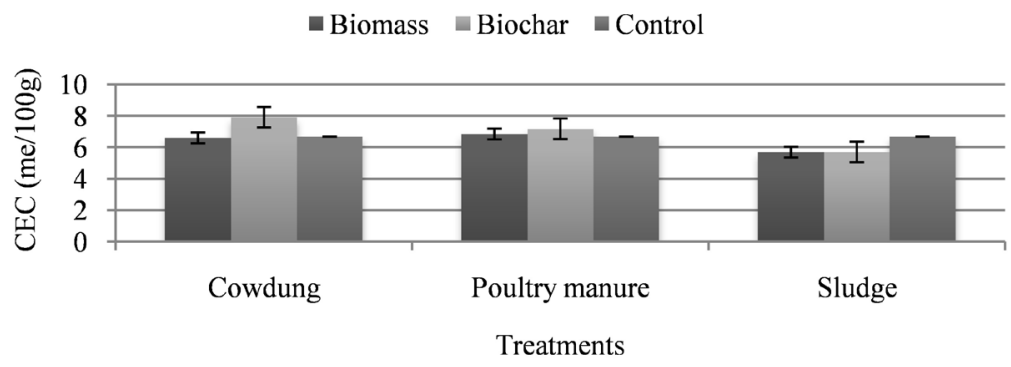

Figure 3. Comparison of CEC between different treatments.

\subsection{Effects on Organic Carbon}

Total organic carbon (TOC) was found same in both sludge biomass and biochar treated soils. In the present study, total organic carbon or soil organic matter (SOM) was found higher or same in biochar treated soils than their respective sources of biomass treated soils. ANOVA study indicated that total soil organic carbon did not differ significantly due to the application of these treatments.

\subsection{Effects on Nitrogen Availability}

Total nitrogen concentration in various treated soils and control soil increased after harvesting of kalmi. Total $\mathrm{N}$ concentration of all three biomass treatments was slightly higher than their respective biochar treatments. The ANOVA test shows significant differential effects of different biomass and biochar treatments 
at $5 \%$ level. The concentrations of nitrogen in treated soil after harvesting of kalmi as affected by different biomass and biochar treatments were presented in Table 2 .

Total $\mathrm{N}$ content of all treated soil and plant shoot were found to be higher than non-treated ones. Uptake of total $\mathrm{N}$ was highest under CM treatment and much higher than its respected biochar treatments (Figure 4). After CM, uptake was found higher in control than other treatments. Except cow dung, nitrogen uptake was higher in biochar treated kalmi plants than their corresponding biomass treated plants. The mean values of total $\mathrm{N}$ concentration of SM treated shoot and control shoot differed significantly at $5 \%$ level as indicated by LSD test.

\subsection{Effects on Phosphorus Availability}

There was an increased available phosphorus concentration in the biochar treated soils than the biomass treated soils. The ANOVA result showed significant differential effect of different biomass and biochar treatments on soil available $\mathrm{P}$ content at $0.1 \%$ level. Table 3 shows the changes in $\mathrm{P}$ concentration of treated soil as affected by different biomass and biochar treatments after harvesting of kalmi and also $\mathrm{P}$ uptake by the plant.

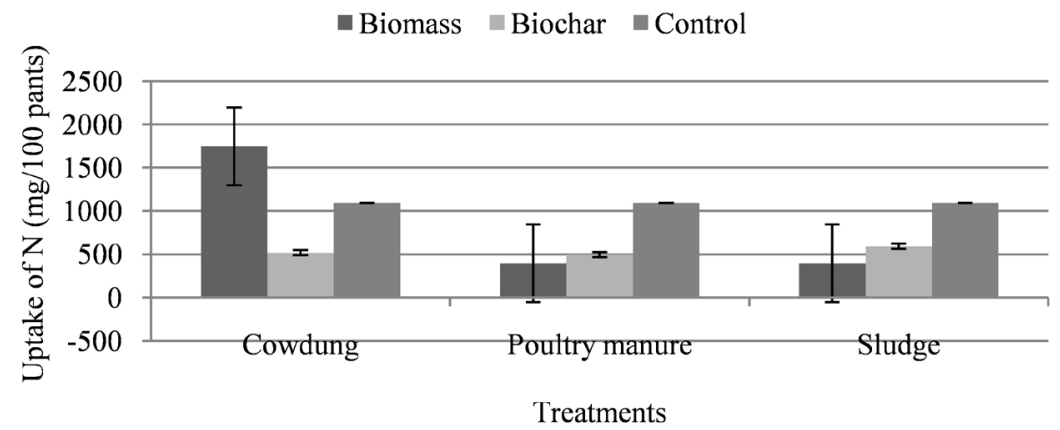

Figure 4. Uptake of total $\mathrm{N}$ by kalmi shoots and leaves.

Table 2. Changes in total $\mathrm{N}$ percentage as affected by different treatments.

\begin{tabular}{|c|c|c|c|c|}
\hline \multicolumn{2}{|c|}{ Treatments } & \multirow{2}{*}{$\begin{array}{c}\text { Total } \mathrm{N} \text { in } \\
\text { soil } \\
(\%)\end{array}$} & \multirow{2}{*}{$\begin{array}{c}\text { Total } \mathrm{N} \text { in } \\
\text { biomass/biochar } \\
(\%)\end{array}$} & \multirow{2}{*}{$\begin{array}{c}\text { Change in total } \mathrm{N} \text { of } \\
\text { treated soil } \\
(\%) \\
0.15\end{array}$} \\
\hline & Biomass (CM) & & & \\
\hline & Biochar (CC) & 0.06 & 1.19 & 0.15 \\
\hline Poultry & Biomass (PM) & 0.06 & 1.67 & 0.16 \\
\hline manure & Biochar (PC) & 0.06 & 1.09 & 0.15 \\
\hline & Biomass (SM) & 0.06 & 0.57 & 0.15 \\
\hline & Biochar (SC) & 0.06 & 0.50 & 0.15 \\
\hline No treatment & Control (Cont) & 0.06 & No treatment & 0.14 \\
\hline
\end{tabular}


Table 3. Changes in $\mathrm{P}$ concentration as affected by different treatments and $\mathrm{P}$ uptake by kalmi.

\begin{tabular}{|c|c|c|c|c|c|c|}
\hline \multicolumn{2}{|c|}{ Treatments } & $\begin{array}{c}\text { Soil available } \\
\text { P (ppm) }\end{array}$ & $\begin{array}{c}\text { Total P in } \\
\text { biomass/biochar } \\
(\%)\end{array}$ & $\begin{array}{l}\text { Change in } \\
\text { Available P of } \\
\text { treated soil } \\
(\mathrm{ppm})\end{array}$ & $\begin{array}{c}\text { Total P of } \\
\text { shoot + leaf } \\
(\%)\end{array}$ & $\begin{array}{c}\text { Total P of } \\
\text { root } \\
(\%)\end{array}$ \\
\hline \multirow[t]{2}{*}{ Cow dung } & $\begin{array}{l}\text { Biomass } \\
(\mathrm{CM})\end{array}$ & 49.16 & 0.41 & 60.10 & 0.069 & 0.032 \\
\hline & Biochar (CC) & 49.16 & 0.54 & 73.70 & 0.072 & 0.085 \\
\hline \multirow{2}{*}{$\begin{array}{l}\text { Poultry } \\
\text { manure }\end{array}$} & $\begin{array}{c}\text { Biomass } \\
(\mathrm{PM})\end{array}$ & 49.16 & 0.70 & 66.50 & 0.076 & 0.054 \\
\hline & Biochar (PC) & 49.16 & 0.79 & 79.67 & 0.091 & 0.085 \\
\hline \multirow[t]{2}{*}{ Sewage sludge } & $\begin{array}{c}\text { Biomass } \\
(\mathrm{SM})\end{array}$ & 49.16 & 0.16 & 62.82 & 0.072 & 0.055 \\
\hline & Biochar (SC) & 49.16 & 0.24 & 68.97 & 0.07 & 0.039 \\
\hline No treatment & $\begin{array}{c}\text { Control } \\
\text { (Cont) }\end{array}$ & 49.16 & No treatment & 64.11 & 0.068 & 0.031 \\
\hline
\end{tabular}

Uptake of total P was highest under CM treatment and it was much higher than its biochar CC treatment (Figure 5). After CM, uptake was found higher in control than other treatments. Except cow dung, P uptake was higher in biochar treated kalmi than their corresponding biomass treated kalmi plants. ANOVA showed significant effect of these treatments on total $\mathrm{P}$ content of both shoot and root at $0.1 \%$ level.

\subsection{Effects on Potassium Availability}

It is apparent that available potassium content of the treated soil decreased from the initial condition and differed differently depending on the treatments. In general there was an increased or same available potassium concentration found in the biochar treated soil than the biomass treated soil (Table 4). Moreover, available $\mathrm{K}$ of $\mathrm{CC}$ treated soil was higher than CM treated soil. The ANOVA test of available $\mathrm{K}$ concentration after harvesting of kalmi showed the presence of significant effect of different biomass and biochar treatments on soil available $\mathrm{K}$ at $5 \%$ level.

The uptake of $\mathrm{K}$ by kalmi shoots and leaves exhibits similar pattern as other two nutrients (nitrogen and phosphorus). Uptake of total $\mathrm{K}$ was highest under $\mathrm{CM}$ treatment and it was much higher than its biochar CC treatment (Figure 6). After CM, uptake was found higher in control than other treatments. Except cowdung, $\mathrm{K}$ uptake was higher in biochar treated kalmi than their corresponding biomass treated kalmi. ANOVA test showed significant effect of these treatments on total $\mathrm{K}$ content of shoot at $0.1 \%$ level.

\subsection{Effects on Sulphur Availability}

It was observed that there was an increased available sulphur concentration in 
cow dung and sludge biochar treated soils than their biomass treated soils whereas for sludge opposite phenomenon happened. Available $\mathrm{S}$ of all treated soils was higher than the non-treated ones. On the contrary, uptake of S by kalmi shoots and leaves exhibits similar pattern as other three nutrients (nitrogen, phosphorus and potassium). Uptake of total S was highest under CM treatment and it was much higher than its biochar CC treatment (Table 5).

\section{Discussions}

The overall $\mathrm{pH}$ of all biochar was found above 7 i.e. alkaline as pyrolized biochar often had a basic $\mathrm{pH}$ [13]. It was reported that a rice-husk biochar produced by gasification process increased final biomass, root biomass, plant height and number of leaves compared to no biochar application [14].

Table 4. Changes in $\mathrm{K}$ concentration of treated soil as affected by different treatments after harvesting kalmi.

\begin{tabular}{|c|c|c|c|c|c|c|}
\hline Trea & atments & $\begin{array}{c}\text { Soil } \\
\text { available K }\end{array}$ & $\begin{array}{c}\text { Total K in } \\
\text { |biomass/biochar }\end{array}$ & $\begin{array}{c}\text { Change in } \\
\text { |available K of } \\
\text { treated soil }\end{array}$ & $\begin{array}{c}\text { Total K of } \\
\text { shoot }+ \text { leaf }\end{array}$ & $\begin{array}{l}\text { Total K of } \\
\text { root }\end{array}$ \\
\hline & Biomass (CM) & 96.14 & 0.49 & 90.26 & 1.38 & 1.035 \\
\hline cov cuing & Biochar (CC) & 96.14 & 0.54 & 92.24 & 1.3 & 2.89 \\
\hline Poultry & Biomass (PM) & 96.14 & 0.44 & 89.93 & 1.46 & 1.72 \\
\hline manure & Biochar (PC) & 96.14 & 0.5 & 90.92 & 1.37 & 1.112 \\
\hline Sewage & Biomass (SM) & 96.14 & 0.34 & 89.60 & 1.31 & 1.744 \\
\hline sludge & Biochar (SC) & 96.14 & 0.34 & 88.61 & 1.4 & 1.226 \\
\hline $\begin{array}{l}\text { No } \\
\text { treatment }\end{array}$ & $\begin{array}{l}\text { Control } \\
\text { (Cont) }\end{array}$ & 96.14 & No treatment & 88.94 & 1.48 & 1.281 \\
\hline
\end{tabular}

Table 5. Changes in S concentration of treated soil as affected by different treatments after harvesting kalmi.

\begin{tabular}{|c|c|c|c|c|c|c|}
\hline \multicolumn{2}{|c|}{ Treatments } & $\begin{array}{c}\text { Soil } \\
\text { available S } \\
(\mathrm{ppm})\end{array}$ & $\begin{array}{c}\text { Total S in } \\
\text { biomass/biochar } \\
(\%)\end{array}$ & $\begin{array}{l}\text { Change in } \\
\text { available S of } \\
\text { treated soil } \\
(\mathrm{ppm})\end{array}$ & $\begin{array}{c}\text { Total S of } \\
\text { shoot + leaf } \\
(\%)\end{array}$ & $\begin{array}{c}\text { Total S of } \\
\text { root } \\
(\%)\end{array}$ \\
\hline \multirow{2}{*}{ Cow dung } & Biomass (CM) & 44.50 & 0.12 & 91.47 & 0.32 & 0.21 \\
\hline & Biochar (CC) & 44.50 & 0.22 & 99.64 & 0.46 & 0.41 \\
\hline \multirow{2}{*}{$\begin{array}{l}\text { Poultry } \\
\text { manure }\end{array}$} & Biomass (PM) & 44.50 & 0.12 & 102.85 & 0.35 & 0.33 \\
\hline & Biochar (PC) & 44.50 & 0.24 & 92.32 & 0.32 & 0.20 \\
\hline \multirow{2}{*}{$\begin{array}{l}\text { Sewage } \\
\text { sludge }\end{array}$} & Biomass (SM) & 44.50 & 0.6 & 92.90 & 0.22 & 0.21 \\
\hline & Biochar (SC) & 44.50 & 0.90 & 97.00 & 0.53 & 0.21 \\
\hline $\begin{array}{c}\text { No } \\
\text { treatment }\end{array}$ & $\begin{array}{l}\text { Control } \\
\text { (Cont) }\end{array}$ & 44.50 & No treatment & 85.36 & 0.33 & 0.22 \\
\hline
\end{tabular}




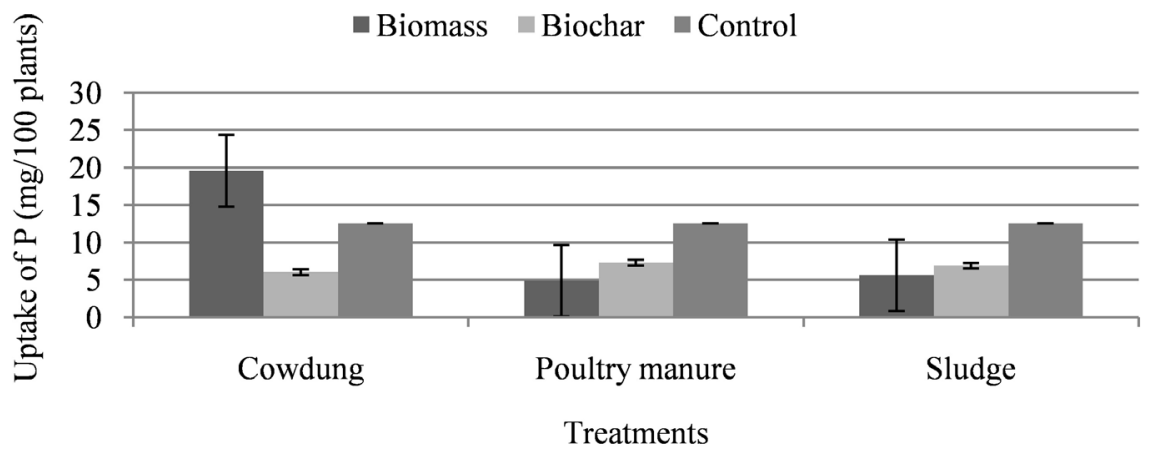

Figure 5. Uptake of P by kalmi shoots and leaves.

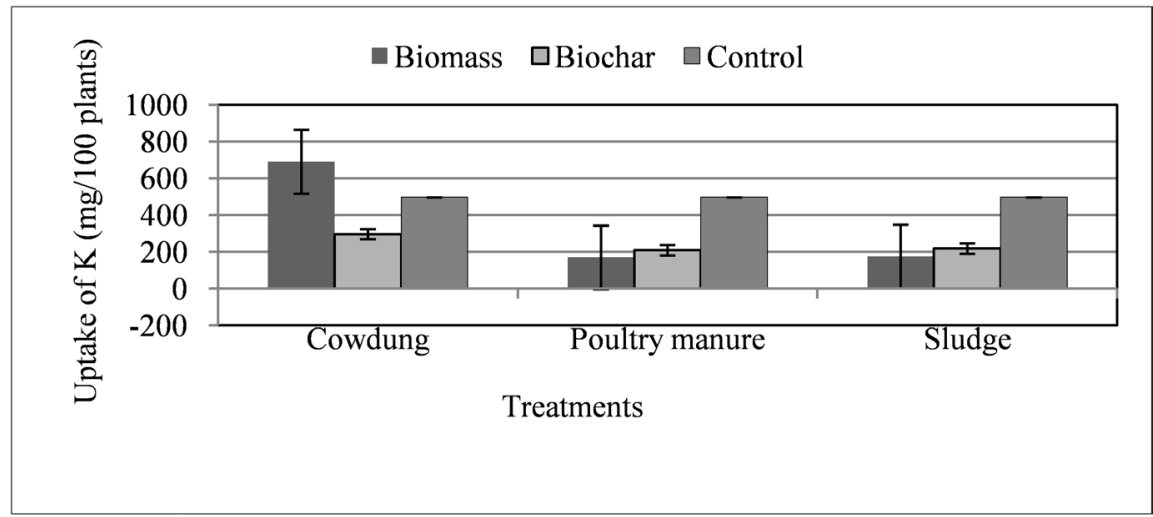

Figure 6. Uptake of K by kalmi shoots and leaves.

Biochar from different sources exhibited different results. Like PC and SC treated kalmi, significant increase in biomass yield of lettuce was observed at $2 \%$ pine forest waste biochar application rate in alkaline loamy sand soil [15]. Even in alkaline soil, biochar application increased growth of lettuce [16]. No effect of biochar amendment was observed for growth of sweet pepper and geranium while coriander shoot growth was increased and lettuce shoot biomass decreased when a biochar was amended with potting soil. In fact, the influence of biochar may vary depending on feedstock of biochar, pyrolysis temperature and test crops [17].

It was found that addition of low rates $(11 \mathrm{t} / \mathrm{ha})$ of char increased CEC indicating the fact that capacity of soils can be increased with char addition [18]. Cation exchange capacity (CEC) could not be increased upon biochar addition while base saturation (BS) was significantly increased due to ash addition with biochar while compost addition significantly increased the CEC [19]. It was found that application of biochar results usually in an increase in total soil carbon as found in the present study and thus acted as a short-term $\mathrm{C}$ sequestration potential in loamy soil compared to sandy soil [20]. Limiting soil $\mathrm{N}$ content by biochar application in $\mathrm{N}$ deficient soils could be due to the high $\mathrm{C} / \mathrm{N}$ ratio, hence it might reduce crop productivity temporarily [21] though pot experiments indicate that biochar reduces $\mathrm{N}$ leaching [22]. It was reported that significantly higher nitrogen retention occur in charcoal-amended soil [23]. Researchers 
mentioned that an increase in soil phosphorus compared with control conditions but increasing levels of charcoal might decrease available $\mathrm{P}$ of the Waimea soil [24]. It was reported that biochar addition could not reduce phosphate leaching during the experiment [19] [21].

Additions of biochar to soils resulted in an average increase in $\mathrm{K}$ concentration compared with control and also alter the balance between the availability of $\mathrm{K}$ and $\mathrm{Mg}$ in the soil and the application of timber mill waste charcoal increased $\mathrm{K}$ concentration and reduced $\mathrm{Mg}$ and $\mathrm{Mn}$ concentrations in leaves of rubber seedlings [25].

\section{Conclusion}

The present study suggests that different sources of biochar exert different effects on plants. Though, nowadays, biochar is gaining widespread credibility to address soil quality and plant development, it is not always as much beneficiary as the biomass. Due to the treatment applications, initial soil status was changed and these changes were strongly correlated with their treatments. Biochar treated soils showed higher CEC than the corresponding biomass treated ones. Organic carbon in char treated soils was increased while organic carbon in biomass treated soils was decreased. Total $\mathrm{N}$ concentration of biomass treatments was higher than biochar treatments. Also $\mathrm{P}, \mathrm{K}$ and $\mathrm{S}$ concentration of the treated soils increased from initial soil after harvesting. Increased concentration of nutrients might be for relative stability, $\mathrm{pH}$, physical properties of biochar, general lack of energy and loss of readily utilizable carbon sources. Source of biochar is also an important factor which needs to be pondered before using it for agricultural purposes.

\section{Conflicts of Interest}

The authors declare no conflicts of interest regarding the publication of this paper.

\section{References}

[1] Bates, A. (2010) The Biochar Solution: Carbon Farming and Climate Change. New Society Publishers, Gabriola Island.

[2] Clapp, J. and Dauvergne, P. (2005) Paths to a Green World: Political Economy of the Global Environment. MIT Press, Cambridge, 314-320.

[3] Lehmann, J.C., Matthias, N., Rillig, J., Thies, A. and Crowley, D. (2011) Biochar Effects on Soil Biota. Soil Biology and Biochemistry, 43, 1816-1821. https://doi.org/10.1016/j.soilbio.2011.04.022

[4] Steiner, C. (2006) Slash and Char as Alternative to Slash and Burn: Soil Charcoal Amendments Maintain Soil Fertility and Establish a Carbon Sink. In: Glaser, B. and Woods, W., Ed., Amazonian Dark Earths. Explorations in Space and Time, Springer Verlag, Heidelberg, 22-28.

[5] Stoyle, A. (2011) Biochar Production for Carbon Sequestration. BS Thesis, Department of Chemical Engineering, Worcester Polytechnic Institute of Chemical Engi- 
neering, Shanghai.

[6] McClellan, T., Deenik, J., Uehara, G. and Antal, M. (2007) Effects of Flashed Carbonized Macadamia Nutshell Charcoal on Plant Growth and Soil Chemical Properties. ASA-CSSA-SSA International Annual Meetings, New Orleans, 6 November 2007, 194.

[7] USDA (United States Department of Agriculture) (1951) Soil Survey Manual. Bureau of Plant Industry, Soils and Agricultural Engineering, 18, 205.

[8] Tan, K.H. (1996) Soil Sampling, Preparation and Analysis. Marcel Dekker, Inc., New York City, 123-126.

[9] Huq, S.M.I. and Alam, M.D. (2005) A Handbook on Analysis of Soil, Plant and Water. Bangladesh-Australia Centre for Environmental Research (BACER-DU). University of Dhaka, Dhaka, 43-50.

[10] Schollenberger, C.J. and Simon, R.H. (1945) Determination of Exchange Capacity and Exchangeable Bases in Soil-Ammonium Acetate Method. Soil Science, 59, 13-24. https://doi.org/10.1097/00010694-194501000-00004

[11] Walkley, A. and Black, I.A. (1934) An Examination of the Degtjareff Method for Determining Soil Organic Matter and a Proposed Modification of the Chromic Acid Titration Method. Soil Science, 37, 29-38. https://doi.org/10.1097/00010694-193401000-00003

[12] Jackson, M.L. (1958) Soil Chemical Analysis. Prentice-Hall, Inc., Englewood Cliffs, $1-498$.

[13] Chan, K.Y. and Xu, Z. (2009) Biochar: Nutrient Properties and Their Enhancement. In: Lehmann, J. and Joseph, S., Eds., Biochar for Environmental Management. Science and Technology, Earthscan, London, 67-84.

[14] Carter, S., Shackley, S., Sohi, S., Suy, T.B. and Haefele, S. (2013) The Impact of Biochar Application on Soil Properties and Plant Growth of Pot Grown Lettuce (Lactucasativa) and Cabbage (Brassica chinensis). Journal of Agronomy, 3, 404-418. https://doi.org/10.3390/agronomy3020404

[15] Artiola, J.F., Rasmussen, C. and Freitas, R. (2012) Effects of Biochar Amended Alkaline Soil on Growth of Romaine Lettuce and Bermuda Grass. Soil Science Society of American Journal, 177, 561-570. https://doi.org/10.1097/SS.0b013e31826ba908

[16] Gunes, A., Inal, A., Taskin, M.B., Osahin, E.C. and Atakol, A. (2014) Effect of Phosphorus Enriched Biochar and Poultry Manure on Growth and Mineral Composition of Lettuce (Lactucasativa L.) Grown in Alkaline Soil. Soil Use Management, 30, $182-188$.

[17] Olszyk, D., Johnson, M., Shiroyama, T., Novak, J., Cantrell, K. and Watts, D. (2014) Effects of Biochar Feedstock and Pyrolysis Temperature on Growth of Corn, Soybean, Lettuce and Carrot. Society for Environmental Toxicology and Chemistry, US Environmental Protection Agency, Vancouver.

[18] Gaskin, J.W., Speir, R.A., Harris, K., Das, K.C., Lee, R.D., Morris, L.A. and Fisher, D.S. (2010) Effect of Peanut Hull and Pine Chip Biochar on Soil Nutrients, Corn Nutrient Status and Yield. Journal of Agronomy, 102, 623-633. https://doi.org/10.2134/agronj2009.0083

[19] Schulz, H. and Glaser, B. (2012) Effects of Biochar Compared to Organic and Inorganic Fertilizers on Soil Quality and Plant Growth in a Greenhouse Experiment. Journal of Plant Nutrition and Soil Science, 175, 410-422. https://doi.org/10.1002/jpln.201100143

[20] Schulz, H., Gerald, D. and Glase, B. (2013) Positive Effects of Composted Biochar on Plant Growth and Soil Fertility. Agronomy for Sustainable Development, 33, 
817-827. https://doi.org/10.1007/s13593-013-0150-0

[21] Lehmann, J., Pereira, J., Steiner, C., Nehls, T., Zechs, W. and Glaser, B. (2003) Nutrient Availability and Leaching in the Archaeological Anthrosols and Ferrosol of the Central Amazon Basin: Fertilizer, Manure and Charcoal Amendments. Plant and Soil, 249, 343-357. https://doi.org/10.1023/A:1022833116184

[22] Chan, K.Y., Van, Z.L. Meszaros, I., Downie, A. and Joseph, S. (2007) Agronomic Values of Green Waste Biochar as a Soil Amendment. Australian Journal of Soil Research, 45, 629-634. https://doi.org/10.1071/SR07109

[23] Steiner, C., Teixeira, W., Lehmann, J., Nehls, T., Blum, W. and Zech, W. (2007) Long Term Effects of Manure, Charcoal and Mineral Fertilization on Crop Production and Fertility on a Highly Weathered Central Amazonian Upland Soil. Plant and Soil, 291, 275-290. https://doi.org/10.1007/s11104-007-9193-9

[24] Biederman, L.A. and Harpole, W.S. (2012) Biochar and Its Effects on Plant Productivity and Nutrient Cycling: A Meta-Analysis. GCB Bioenergy, 5, 202-214. https://doi.org/10.1111/gcbb.12037

[25] Dharmakeerthi, R.S., Chandrasiri, J.A.S. and Edirimanne, V.U. (2012) Effect of Rubber Wood Biochar on Nutrition and Growth of Nursery Plants of Hevea brasiliensis Established in Ultisol. SpringerPlus, 1, 84.

https://doi.org/10.1186/2193-1801-1-84 